\title{
Formação de professores a distância pela Universidade Aberta do Brasil: democratização e acesso ou massificação e mercantilização da formação? ${ }^{1}$
}

\author{
Distance teacher education by the Open University of Brazil: democratization and access or \\ massification and commodification of training? \\ Formación docente a distancia por la Universidad Abierta de Brasil: ¿democratización y acceso o \\ masificación y mercantilización de la formación?
}

\section{Resumo}

Este trabalho tem como objetivo discutir os caminhos percorridos pela formação de professores na Universidade Aberta do Brasil (UAB) e o quanto as premissas de Educação a Distância (EaD) e da UAB se aproximam ou distanciam da proposta de acesso e democratização do ensino em contrapartida ao processo de mercantilização e massificação da formação. Foram analisadas teses no Catálogo de Teses da CAPES que versaram sobre políticas educacionais no contexto da UAB entre 2006 e 2016, bem como documentos e leis que tratam sobre o tema aqui discutido. Verificamos que a UAB foi criada com o propósito de atender à crescente demanda por formação de professores, à interiorização, ao acesso e democratização da educação pública superior no país. Contudo, o modelo projetado pra UAB é embasado num sistema precário de pagamento de bolsas de pesquisa para docentes e tutores e caracterizado por um processo de descontinuidade de financiamento que levou as instituições à busca do barateamento dos cursos com adoção de menor número de tutores, material didático e visita aos polos de apoio presencial. Houve um processo de desresponsabilização do Estado com o ensino superior transferindo aos municípios e estados a reponsabilidade com esta formação sem a contrapartida necessária para uma formação emancipatória. Assim, o Programa mais se aproximou ao modelo massivo-mercantil do que à democratização.

Palavras-chave: Educação a distância; Universidade Aberta do Brasil; Formação de professores; Democratização e acesso; Massificação e mercantilização.

\begin{abstract}
This paper aims to discuss the paths taken by teacher training at the Open University of Brazil (UAB) and how much the premises of Distance Education $(\mathrm{EaD})$ and $\mathrm{UAB}$ approach or distance from the proposal of access and democratization of education in return to the process of commodification and massification of training. Theses were analyzed in the CAPES Thesis Catalog that dealt with educational policies in the context of UAB between 2006 and 2016, as well as documents and laws dealing with the topic discussed here. We found that the UAB was created with the purpose of meeting the growing demand for teacher training, interiorization, access and democratization of higher public education in the country. However, the model designed for UAB is based on a precarious system of payment of research grants for teachers and tutors and characterized by a process of discontinuity of funding that led the institutions to search for cheaper courses with the adoption of a lower number of tutors, material course and visit to the face-to-face support centers. There was a process of State's lack of responsibility with higher education, transferring responsibility for this training to municipalities and states without the necessary counterpart for an emancipatory training. Thus, the Program was closer to the massive-mercantile model than to democratization.
\end{abstract}

Keywords: Distance education; Open University of Brazil; Teacher training; Democratization and access; Massification and commodification.

\section{Resumen}

Este trabajo tiene como objetivo discutir los caminos tomados por la formación docente en la Universidad Abierta de Brasil (UAB) y en qué medida las premisas de la Educación a Distancia (EaD) y la UAB se acercan o alejan de la propuesta de acceso y democratización de la educación en retorno al proceso. de mercantilización y masificación de la formación. Las tesis fueron analizadas en el Catálogo de Tesis CAPES que abordó las políticas educativas en el

\footnotetext{
${ }^{1}$ Texto adaptado da Tese de doutorado do autor. (Santos Neto, 2019).
} 
contexto de la UAB entre 2006 y 2016, así como documentos y leyes que abordan el tema aquí discutido. Descubrimos que la UAB se creó con el propósito de atender la creciente demanda de formación, interiorización, acceso y democratización docente de la educación pública superior en el país. Sin embargo, el modelo diseñado para la $\mathrm{UAB}$ se basa en un precario sistema de pago de becas de investigación para profesores y tutores y caracterizado por un proceso de discontinuidad de financiación que llevó a las instituciones a buscar cursos más económicos con la adopción de menos tutores, curso material y visita a los centros de apoyo presencial. Hubo un proceso de desresponsabilidad del Estado con la educación superior, transfiriendo la responsabilidad de esta formación a municipios y estados sin la contraparte necesaria para una formación emancipadora. Así, el Programa se acercó más al modelo masivo mercantil que a la democratización.

Palabras clave: Educación a distancia; Universidad Abierta de Brasil; Formación de professores; Democratización y acceso; Masificación y mercantilización.

\section{Introdução}

O Programa Universidade Aberta do Brasil foi criado por meio do Decreto ${ }^{\circ} 5.800$ de 08 de junho de 2006. Surgiu com a proposta de interiorizar e democratizar o acesso a cursos superiores a distância. Contudo, ao longo do tempo, sofreu com diversos problemas financeiros e políticos vivenciando diversas fases ao longo de sua existência.

Nesse sentido, a UAB vivenciou uma fase de expansão caracterizada pelos primeiros anos após sua implementação (2006 a 2012), uma segunda fase de retração, com os cortes dos repasses de custeio para as IES, na qual os parcos recursos de custeio não eram suficientes para garantir o funcionamento dos cursos com a estrutura adequada de tutoria, material didático impresso e visita aos polos, obrigando as Instituições Públicas de Ensino Superior (IPES) a executarem um processo de redução de custos e caminharem no sentido da massificação dos conteúdos (2013 a 2016) e uma terceira fase de indagação e dúvidas sobre sua continuidade (2017 em diante), quando os recursos continuaram escassos e aumentou a desconfiança sobre a continuidade do programa (Santos Neto, 2019).

Como questão central desejamos conhecer se a UAB apoiada nas ofertas de cursos a distância promoveu o acesso e democratização do ensino ou a mercantilização e massificação dos cursos baseadas em premissas neoliberais? Para tanto, elaboramos uma pesquisa no Catálogo de Teses e Dissertações da CAPES e selecionamos teses que versaram sobre políticas relacionadas à UAB de 2006 a 2017. Esses autores conversam com outros autores conceituados da área e desvelam ao longo do texto aspectos inerentes à formação a distância de professores e à Universidade Aberta do Brasil. Como método, nos apoiamos no materialismo histórico dialético por acreditar que todo acontecimento é resultado de um processo histórico e que interfere nas situações futuras num processo contínuo de mudança.

\section{Metodologia}

A presente pesquisa seguiu a abordagem qualitativa, uma vez que buscou conhecer aspectos e fenômenos pois os dados analisados são "ricos em pormenores descritivos relativamente a pessoas, locais e conversas, e de complexo tratamento estatístico" (Bogdan \& Biklen, 1999, p. 16). Nesse sentido quanto aos procedimentos técnicos, realizamos uma pesquisa bibliográfica em livros, revistas, bem como uma pesquisa documental em documentos e leis publicadas no Brasil acerca do tema. Foi elaborada uma pesquisa no Catálogo de Teses e Dissertações da Coordenação de Aperfeiçoamento de Pessoal de Nível Superior (CAPES), no qual identificamos as publicações sobre políticas educacionais no âmbito da UAB no período de 2006 a 2016. Como descritores de pesquisa utilizamos os seguintes: a) Universidade Aberta do Brasil; b) UAB; c) Educação a distância e d) EaD. Após seleção das teses e dissertações obtivemos o seguinte resultado: 
Quadro 1 - Resultado da pesquisa sobre teses e dissertações com os descritores.

\begin{tabular}{|c|c|c|c|c|c|c|c|}
\hline \multirow{3}{*}{$\begin{array}{l}\text { Tipo de } \\
\text { trabalho }\end{array}$} & \multicolumn{6}{|c|}{ Descritores } & \multirow{3}{*}{$\begin{array}{l}\text { Total } \\
\text { Geral }\end{array}$} \\
\hline & \multicolumn{3}{|c|}{ Universidade Aberta do Brasil } & \multicolumn{3}{|c|}{ Educação a Distância } & \\
\hline & $\begin{array}{c}\text { Universidade } \\
\text { Aberta do Brasil } \\
\end{array}$ & UAB & $\begin{array}{l}\text { Total } \\
\text { UAB } \\
\end{array}$ & $\begin{array}{c}\text { Educação a } \\
\text { Distância }\end{array}$ & EaD & $\begin{array}{l}\text { Total } \\
\text { EaD }\end{array}$ & \\
\hline Teses & 100 & 118 & 218 & 818 & 508 & 1.326 & 1.544 \\
\hline Dissertações & 226 & 237 & 463 & 2.481 & 1.995 & 4.476 & 4.939 \\
\hline Total & 326 & 355 & 681 & 3.299 & 2.503 & 5.802 & 6.483 \\
\hline
\end{tabular}

Fonte: Santos Neto (2019, p. 46)

Após leituras dos resumos, chegamos a um total de 39 teses que versavam sobre políticas educacionais no âmbito da UAB. Na parte 3 deste trabalho, trazemos as principais revelações dessas pesquisas sobre o aspecto da expansão da UAB e EaD no Brasil, com foco no aspecto do acesso e democratização e da massificação e mercantilização da formação de professores.

Como método elegemos o materialismo histórico dialético uma vez que, nesta concepção materialista, deve ser considerado o fator histórico, pois "o homem, enquanto ser social e histórico, determinado por contextos econômicos, políticos e culturais, é o criador da realidade social e transformador desses contextos" (Gomide, 2014, p. 129). Assim, torna-se necessária a análise que parta de um contexto histórico e busque a transformação dos fenômenos sociais.

Como metodologia analítica adotamos a triangulação de dados que consiste na análise, verificação de conversão e divergências entre as mesmas e discussão das diversas fontes de pesquisa utilizadas. Assim, o texto propõe a conversa entre os documentos analisados, as teses estudadas e os autores trazidos no âmbito da discussão.

\section{A expansão da Educação a Distância e da UAB - Alguns Condicionantes}

Como justificativa à utilização da Educação a Distância $(\mathrm{EaD})$ na formação superior paira o discurso da democratização da educação, promoção da interiorização e do acesso por parte da população que não o teria, sobretudo por questões geográficas e temporais. A essa questão de tempo e espaço, Levy (1999, p. 49), aponta que

o ciberespaço encoraja um estilo de relacionamento quase independente dos lugares geográficos (telecomunicação, telepresença). [...] apenas as particularidades técnicas do ciberespaço permitem que os membros de um grupo humano (que podem ser tantos quantos quiser) se coordenem, cooperem, alimentem e consultem uma memória comum, e isto em quase tempo real, apesar da distribuição geográfica e da diferença de horários.

Esse mecanismo pelo qual opera a educação a distância permite, portanto, a compressão do tempo e do espaço, podendo, por meio da internet, atingir pessoas em locais onde não há curso presencial. Esse talvez seja o principal argumento dos entusiastas da EaD. Por outro lado, Castells (2003, p. 225) aponta que "a internet é de fato uma tecnologia da liberdade mas pode libertar os poderosos para oprimir os desinformados, pode levar à exclusão dos desvalorizados pelos conquistadores de valor. Nesse sentido geral, a sociedade não mudou muito".

Reis (2002) aponta que, por meio da EaD, é possível democratizar o acesso à educação, a partir do momento em que ela abre oportunidades distintas do ensino presencial, perfazendo um trabalho de complementaridade e não de oposição a essa modalidade. Por outro lado, chama-se a atenção para o fato de que a EaD poderá ser utilizada como mecanismo excludente, planejada por uma elite educacional e ofertada por instituições privadas sob a ótica do mercado às classes subalternas.

Nesse sentido, Santos (2000, p.39) aponta que, "todavia, nas condições atuais, as técnicas da informação são principalmente utilizadas por um punhado de atores em função de seus objetivos particulares", demonstrando a preocupação com a utilização das tecnologias de informação e comunicação no final do século passado. Em contrapartida, Martelli (2003, p. 
149) aponta que,

diante desse quadro, a Educação a Distância vem se consolidando como uma das alternativas de democratização do acesso à educação superior, contribuindo no atendimento da demanda educacional requerida pela sociedade contemporânea, apresentando traços compatíveis com as atuais orientações educacionais como a reflexibilidade, a interdisciplinaridade, a interatividade, a autonomia e a qualidade.

Devemos destacar que essas "novas orientações educacionais" são as mesmas propostas pelos organismos internacionais, nesse caso pela UNESCO, que "tem defendido muito a ideia da educação continuada, considerando-a chave para a elaboração das políticas educacionais do futuro" (Martelli, 2003, p. 21). A autora complementa que a "EaD vem se constituindo em uma modalidade promissora para o desenvolvimento de projetos que visam não somente à formação continuada, mas também à inicial" (Martelli, 2003, p. 21).

A autora reforça o caráter de democratização da EaD e também corrobora Reis (2002), no sentido de que, "enquanto alternativa pedagógica, a EaD não tem por objetivo substituir a educação presencial, pelo contrário, pode contribuir em um trabalho que potencialize as oportunidades no âmbito da formação humana e profissional, inicial e continuada" (Martelli, 2003, p. 149).

Pessôa (2006, p. 217) acredita numa EaD que "procura formar, dentro de sua especificidade de tempo e espaço diferentes daqueles constituídos na educação regular, um cidadão crítico e emancipado”. Ainda segundo Pessôa (2006, p. 217),

a educação deveria ter o trabalho como princípio educativo, assim, as novas tecnologias inseridas na modalidade à distância haveriam de indicar novas concepções de homem, de mundo, de sociedade e de ação profissional, bem diferente destas atuais referências, imbricadas numa concepção de trabalho pautada pela produtividade e quantificação.

Nesse sentido, a preocupação central é que, para que a EaD atinja a emancipação e a justiça social, é preciso se distanciar das premissas neoliberais, pois "a ideologia neoliberal acentua a degradação do homem e sua submissão aos interesses do capital financeiro, produzindo lógicas de mercado que privilegiam centros produtores e periferias de dependência e consumo" (Pessôa, 2006, p. 217). Enquanto havia nas universidades públicas "uma certa e inconsequente manifestação de desinteresse" pela criação de uma política de $\mathrm{EaD}$, as universidades particulares o faziam com interesses mercadológicos (Pessôa, 2006). A autora conclui:

Por fim, resta-nos afirmar que, a título de simplificação, temos clareza que a EAD no Brasil esteve presa a dois projetos - o de resgatar o déficit histórico de educação e o de promover um acesso comercial à escolarização. A atual política de gestão de EAD, tanto em nível federal como estadual, sucumbe a interesses de uma política neoliberal e mercantilista que pode ser considerada hegemônica. (Pessôa, 2006, p. 223 - grifos nossos).

Uma das razões para o modesto empenho das universidades públicas na implementação e desenvolvimento da EaD se deu, também, por questões de resistência a essa modalidade, alegando questões de qualidade inferior. O recente crescimento das tecnologias digitais da informação e comunicação, assim como o despreparo de muitos professores promoveriam uma considerada resistência à mediação da aprendizagem por meio da internet e do computador. Outro aspecto seria o próprio preconceito de professores em relação à modalidade. A respeito disso, Mill (2016, p. 443) aponta que

apesar dos cenários positivos relacionados à Educação a Distância, é importante indicar que a modalidade passou por diversas dificuldades, mesmo após a sua inclusão na legislação e mesmo antes de entrar em crise. $O$ dilema da má fama herdada de experiências anteriores e, por conseguinte, o preconceito investido contra a EaD estão entre os aspectos mais depreciativos vividos pela modalidade até a virada do século. Ainda hoje, há preconceito, mas com menor intensidade, e progressivamente a modalidade tem ganhado adesão de estranhos. (grifos do autor). 
Com o propósito de direcionar caminhos para a condução de cursos superiores a distância, preocupado com a qualidade e com instrumentos de avaliação de cursos, o MEC publicou em 2003 os referenciais de qualidade para a educação a distância.

os referenciais se assemelham aos que se exigem para os cursos presenciais. Isto é fato e reflete uma visão de que, com mais ou menos presença em uma sala de aula, o que importa para o cidadão e para a sociedade brasileira é ter uma formação pautada em inquestionável padrão de qualidade. (Brasil, 2003, p. 4).

Percebemos a constante comparação, à época, dos cursos a distância com os cursos presenciais. Embora não seja o interesse dos pesquisadores em EaD de suscitar uma competição, isso já acontecia e continuaria ocorrendo, sobretudo em função da tentativa da EaD se firmar como modalidade de ensino e não como método de ensino.

Nesse contexto, a tentativa de mostrar a qualidade de cursos a distância ocupou importante espaço de discussão, a exemplo de Gomes (2007) que elaborou um estudo comparativo entre formação de professores presencial e a distância, concluindo que ambas as formações preparariam igualmente ao exercício do magistério e que investimentos em $\mathrm{EaD}$ seriam igualmente ou mais vantajosos para a formação inicial e continuada de professores.

Contudo, Gomes (2006, p. 9) revelou em sua pesquisa que,

de forma geral, reconhece-se o curso como uma opção válida, mas considera-se que estará mais bem formado o professor cujo curso é oferecido na modalidade presencial. O estudo mostrou que o curso da UFES na modalidade EAD é apropriado para aqueles que não podem estar presentes em sala de aula e atende ao princípio das "oportunidades regidas pela equidade", contribuindo para a desmistificação de uma modalidade de ensino sobre a outra.

Em contraposição, a autora traz o fato de que os estudantes ingressantes no ensino presencial tiveram um processo seletivo mais rigoroso do que aqueles ingressos na EaD, levantando a hipótese de que a diferença de desempenho entre ambos não seria exclusivamente pela modalidade da graduação, mas também pelo histórico acadêmico do ingressante. Acrescenta que embora não tenha investigado a fundo essa questão, notou-se ao longo do curso maior dificuldade nos estudantes de $\mathrm{EaD}$ "9,3\% dos estudantes $\mathrm{EaD}$, após quatro anos de curso, encontram-se na faixa de desempenho muito baixo, inferior a $40 \%$ no teste de Língua Portuguesa e de Matemática contra 5,1\% do contingente de estudantes da Presencial" (Gomes, 2007, p. 160).

Embora o foco não seja a comparação entre presencial e a distância, há uma visão de que a EaD seria capaz de formar melhor do que o ensino presencial. Esse fato se apoia na ideia de que as tecnologias digitais da informação e comunicação vieram para ficar e mudar o rumo da sociedade. Castells (2003, p. 225) aponta que "todos os domínios da vida social estão sendo modificados pelos usos disseminados da internet. Uma nova forma social, a sociedade de rede, está se constituindo em torno do planeta".

Guiotti (2007) compreende que a educação a distância seria uma forma mais barata do que o ensino presencial, sobretudo nas IES públicas, nas quais "o custo do estudante é muito mais alto, pois além de não se cobrarem taxas, na maioria das vezes são oferecidos outros serviços como alimentação subvencionada, facilidades de moradia, etc" (Guiotti, 2007, p. 211). Em contrapartida, "a oferta massiva de vagas em cursos a distância sem o devido planejamento e compromisso dificilmente conta com a quantidade de professores e tutores preparados para assumir essas funções" (Guiotti, 2007, p. 2120).

A visão de educação como custo perpassa pela falácia neoliberal, uma vez que educação é investimento. Pensar em promover EaD para baratear a formação vai ao encontro da proposta de massificação e mercantilização da formação docente. Nesse sentido, para se pensar numa EaD capaz de ofertar cursos com qualidade, jamais poderá utilizar a redução de custos como justificativa para tal, uma vez que poderia penalizar a parcela da população que teria acesso apenas a essa modalidade de ensino, o que não contribuiria para a inclusão, mas sobretudo para a exclusão desse cidadão. 
Costa (2010, p. 166) destaca a "necessidade de se institucionalizar a modalidade de educação no interior das IES que integram o Sistema UAB, com a definição de um arcabouço legal mais consistente que atenda às especificidades dos cursos ofertados em uma modalidade distinta do ensino presencial". Para a autora, a EaD necessita de um compromisso efetivo por parte do Governo central, de forma que as ações desempenhadas pelas IPES não se percam sobretudo pela falta de recursos e política assertiva.

São destacados os principais problemas acerca do Programa UAB levantados por diversos autores. Costa (2010) salienta que as críticas "indicam questões que devem ser constantemente observadas para que o Sistema UAB possa representar mais do que um programa de governo, configurando-se realmente como um programa de Estado, o que pressupõe a oferta de educação superior" (Costa, 2010, p. 166). O principal fundamento é que enquanto o sistema UAB for considerado como programa de governo e a remuneração do pessoal feita por meio de Bolsa, os riscos de descontinuidade são frequentes.

O Governo Lula da Silva (2003-2010), embora se apresente como alternativa para promover rupturas em relação ao projeto de sociedade e de educação dos governos anteriores, não disputou, com esses, um projeto de sociedade antagônico, e ao estabelecer políticas, programas e ações para as classes menos favorecidas e excluídas socialmente, em sintonia, e de acordo com os interesses das elites brasileiras, não disputou também um projeto educacional alternativo e antagônico àqueles apresentados no curso histórico em que se colocava como oposição. Logo, as políticas de $\mathrm{EaD}$ voltadas à formação de professores da $\mathrm{EB}$, com destaque para a $\mathrm{UAB}$, programa estratégico no campo investigado, foram concebidos e instituídos em um percurso controvertido entre as lutas da sociedade, as propostas do governo e as ações e omissões no exercício do poder[...]. (Medeiros, 2012, p. 7).

Embora tenha sido um governo considerado de envergadura social, não se desfez da agenda neoliberal, pelo contrário, o modelo "escolhido" para a formação de professores aponta para um projeto neoliberal travestido no discurso do acesso e interiorização, promove uma forma precária de trabalho docente - a tutoria presencial e virtual remunerada por intermédio de bolsa de pesquisa, regulamentada pelo Fundo Nacional de desenvolvimento da Educação (FNDE, 2006) e pela Coordenação de Aperfeiçoamento de Pessoal do Ensino Superior (CAPES)². A regulamentação se torna necessária para "legalizar" tal modelo.

Estas medidas tanto podem obedecer (e serem justificadas), de um ponto de vista mais técnico, em função de critérios de modernização, desburocratização e combate à "ineficiência" do Estado ("new public management"), como serem justificadas por imperativos de natureza política, de acordo com projetos neoliberais e neoconservadores. (Barroso, 2005 p. 726).

Nesse sentido, a regulamentação reforça (justifica) a ação neoliberal.

No domínio da educação, a influência das ideias neoliberais fez-se sentir quer por meio de múltiplas reformas estruturais, de dimensão e amplitude diferentes, destinadas a reduzir a intervenção do Estado na provisão e administração do serviço educativo, quer por meio de retóricas discursivas (dos políticos, dos peritos, dos meios de informação) de crítica ao serviço público estatal e de "encorajamento do mercado".

Este "encorajamento do mercado" traduz-se, sobretudo, na subordinação das políticas de educação a uma lógica estritamente económica ("globalização"); na importação de valores (competição, concorrência, excelência etc.) e modelos de gestão empresarial, como referentes para a "modernização" do serviço público de educação; na promoção de medidas tendentes à sua privatização. (Barroso, 2005, p. 741).

Portanto, o formato em que foi criada a UAB, como programa de governo, com insegurança e insuficiência de recursos, trabalho precarizado e a desresponsabilização do governo central por meio da transferência da responsabilidade da formação em nível superior aos estados e municípios na tentativa de redução de custos, acaba sendo incapaz de atender à demanda por cursos superiores e abre espaço para ação da iniciativa privada.

${ }^{2}$ Lei - 11.273/2006 - Autoriza a concessão de bolsas de estudo e de pesquisa a participantes de programas de formação inicial e continuada de professores para a educação básica. 
Essa (des) responsabilização é outra característica do Estado neoliberal, uma vez que, por meio de uma descentralização disfarçada, transfere a responsabilidade do sucesso escolar aos agentes educacionais (pais, estudantes, professores, gestores, etc.), pois essa "perspectiva gerencialista é concebida como uma mera transferência de responsabilidade do ente federativo para as instâncias inferiores, com a falta de financiamento para os níveis estadual e local agrava-se o quadro de degradação dos serviços públicos. (Wellen, 2001, p. 108).

Isto obrigou as IPES a uma dependência política para a liberação dos recursos para a prática de EaD, uma vez que eles não são repassados na planilha orçamentária da instituição. Assim, além da insuficiência de recursos, os gestores lidam com a incerteza da continuidade dos financiamentos, como podemos verificar no Ofício n ${ }^{\circ}$ 245/2018-GAB/PR/CAPES, de 01 de agosto de 2018.

[...] foi repassado à CAPES um teto limitando seu orçamento para 2019 que representa um corte significativo em relação ao próprio orçamento de 2018, fixando um patamar muito inferior ao estabelecido pela LDO. Caso seja mantido esse teto, os impactos serão graves para os Programas de Fomento da Agência. Citamos aqui algumas das principais consequências nas linhas de atuação da Capes:

Suspensão dos pagamentos de 105 mil bolsistas a partir de agosto de 2019, acarretando a interrupção do Programa Institucional de Bolsas de Iniciação à Docência (Pibid) (Edital n 7/2018), do Programa de Residência Pedagógica (Edital $n^{\circ}$ 7/2018) e do Programa Nacional de Formação de Professores da Educação Básica (Parfor) (Edital no 19/2018).

Interrupção do funcionamento do Sistema Universidade Aberta do Brasil (UAB) e dos mestrados profissionais do Programa de Mestrado Profissional para Qualificação de Professores da Rede Pública de Educação Básica (ProEB), com a suspensão dos pagamentos a partir de agosto de 2019, afetando os mais de $\mathbf{2 4 5 . 0 0 0}$ beneficiados (estudantes e bolsistas - professores, tutores, assistentes e coordenadores) que encontram-se inseridos em aproximadamente 110 IES, que ofertam em torno de 750 cursos (mestrados profissionais, licenciaturas, bacharelados e especializações), em mais de 600 cidades que abrigam polos de apoio presencial. (Brasil, 2018 - grifos do documento).

Essa limitação orçamentária presente na estrutura da UAB desde 2013 obrigou as IES a alterarem os projetos de seus cursos com menor número de tutores, eliminação do material didático impresso, redução do número de visita de acompanhamento e monitoramento aos polos de apoio presencial (Santos Neto, 2019).

Essa preocupação com financiamento e funcionamento da UAB já era recorrente desde seu início tornando-se outra linha de abordagem nas pesquisas sobre a UAB no país a partir de 2009. Nesse sentido, a preocupação dos autores que no início do século questionavam o modelo de formação de professores por meio da UAB embasava-se não apenas em aspectos pedagógicos e de qualidade da modalidade, mas também em fatores políticos e estruturais. De acordo com Osório (2010), a migração da formação de professores para outros espaços como os polos de apoio presenciais dos município e estados descerravam novas condicionantes de formação distanciando-a da universidade com centralidade na internet, massificando e flexibilizando a formação.

O caráter das propostas atuais de cursos a distância, nos quais os encontros presenciais acontecem apenas uma vez por semana, em caráter não obrigatório, sendo apenas a avaliação obrigatoriamente presencial, está em sintonia com o sentido de responsabilização que se imprime às políticas atuais. Responsabiliza- se os estudantes, que já chegam a estes cursos em condições desiguais frente aos demais estudantes das universidades, sem que se ofereça, pelas condições de ensino - a mediação dos tutores e a ênfase em estudos individualizados e solitários -, possibilidades de auto-superação de suas limitações, resultantes de seu percurso na educação básica. (Freitas, 2007, p, 1.212 - grifos da autora).

Percebemos que a estrutura hegemônica do capital e da política neoliberal se faziam presentes nos modelos de formação, sendo que o conjunto de argumentos para adoção de premissas neoliberais na formação docente dominava sobre os aspectos formativos - comprometendo a práxis da educação emancipatória. A formação emancipadora e promotora de justiça social necessita, portanto, da eliminação das amarras do poder hegemônico do capital. Assim, a EaD disfarçada no discurso do 
acesso e da interiorização surge, para muitos autores, como aquela capaz de resolver as questões de formação.

A Educação a Distância (EaD) alia a Educação às mais modernas Tecnologias da Informação e Comunicação TICs, fazendo com que o processo de ensino aprendizagem possa ser levado a uma maior parcela de pessoas com a qualidade necessária ao engrandecimento das mesmas como seres humanos. Assim, a Educação a Distância, por suas características específicas de superação das distâncias físicas e pela utilização das diversas tecnologias disponíveis, é um importante instrumento para a concretização do Direito Fundamental à Educação de todos, especialmente em nosso País, em virtude de sua vastidão territorial, bem como de seus obstáculos naturais, além da possibilidade de se atingir um maior número de receptores com a qualidade que o ensino deve ter, possibilitando a todos a necessária dignidade. (Veltroni, 2011, p. 7).

No entanto, acesso não significa libertação, emancipação ou dignidade. "Seria realmente um absurdo esperar uma formulação de um ideal educacional, do ponto de vista da ordem feudal em vigor, que considere a hipótese da dominação dos servos, como classe, sobre os senhores da bem-estabelecida classe dominante" (Mészáros, 2008, p. 27).

Se por um lado o acesso promovido pela ampliação de vagas é visto como garantia do direito à educação, por outro o modelo educacional vigente cerceia os grupos sociais menos favorecidos, dando-lhe uma educação de qualidade "duvidosa ou inferior”, uma vez que a "a formação superior, para a grande maioria, dar-se-á nas instituições privadas, como bolsistas, ou nos cursos a distância, em polos da UAB, nos cursos de pedagogia e cursos normais superiores, concomitante ao trabalho na educação básica" (Freitas, 2007, p. 1.206).

A EaD tem se constituído uma oportunidade de estudos para estudantes que dependem do trabalho, permitindo que realizem seus estudos em espaços e tempo diferentes do ensino presencial (Guiotti, 2007). Contudo, além de igualdade de oportunidades, o Estado deve oferecer igualdade de condições para todos e todas. Assim, a expansão do acesso atende sumariamente aos preceitos do capital, principalmente no tocante a respostas a organismos multilaterais, porém não se mostra eficaz na busca da justiça social, uma vez que a oferta desses cursos pelo Estado está limitada a um rol de cursos, sobretudo de formação de professores, e financiamento descontínuo.

As políticas da UAB/CAPES/PARFOR têm incrementado a formação inicial de professores da educação básica sob o argumento de preparar professores sem retirá-los do serviço; de forma centralizada, porque parte está distribuída pelo interior do país, além de que a exigência reduzida de instalações físicas para EAD nos cursos, vem sendo conduzidas por no mínimo um professor pesquisador - em geral servidor público de uma IES - e professores tutores com formação menos qualificada e submetidos condições e desvalorização de seu trabalho. Esse cenário contribuiu para o barateamento da EAD e da formação de professores para a educação básica. (Nascimento, 2012, p. 321).

Devemos salientar que mesmo com o barateamento dos cursos EaD por parte do Estado, a continuidade no financiamento era incerta. Esse fato promoveu ao longo do tempo uma limitação na oferta pública de EaD e o incremento da oferta por IES privadas (INEP, 2016).

A adoção de políticas neoliberais na formação docente, conduzindo-a a um processo de desresponsabilização do estado e privatização da formação, tem ocorrido nos Estados Unidos e em outros países, com apoio do Banco Mundial (Zeichner, 2013). Esse processo de substituição da formação pública pela privada conduz a um aumento indiscriminado de cursos de licenciatura a distância nas IES privadas no Brasil, como mostram os dados dos censos da educação superior do INEP.

De 2009 a 2019 houve aumento de 20,28\% das matrículas em cursos presenciais e de 192,35\% nos cursos a distância. Nesse mesmo período, a porcentagem de matrículas em EaD nos cursos superiores saltou de 16,38 para 39,82. Desde 2018 as matrículas em cursos de licenciatura distância superaram as matrículas nos cursos presenciais, sendo que em 2019, 53,3\% das matrículas em cursos de licenciatura foram realizadas em cursos a distância (Brasil, 2020). 
Essas políticas se mostram atreladas a um propósito de formação no sentido de atender às demandas de mercado e que representam uma tecnologia e política de controle e regulação social. [...] estão focadas na competência para a empregabilidade, fazendo com que, no plano educativo, também se vivencia uma postura compatível com o ideário do mercado. (Ramos, 2013, p. 88).

A dinâmica do capital se mostra cada vez mais hegemônica, permeando todos os segmentos da sociedade, fazendo da educação e da tecnologia aliados importantes.

O objetivo central dos que lutam contra a sociedade mercantil, a alienação e a intolerância é a emancipação humana. A educação, que poderia ser uma alavanca essencial para a mudança, tornou-se instrumento daqueles estigmas da sociedade capitalista: "fornecer os conhecimentos e o pessoal necessário à maquinaria produtiva em expansão do sistema capitalista, mas também gerar e transmitir um quadro de valores que legitima os interesses dominantes". (Sader, 2008, p.13).

Nesse sentido, ao se pensar na formação de educadores deve-se procurar promover a emancipação humana e, para tanto, romper com a lógica do capital. Nessa linha, o formato predominante de formação massiva e racional intermediado pelas TDIC adotado pela EaD mercantil vai em sentido contrário ao da formação emancipadora. A tecnificação da educação, por meio das TDIC, foi predominante nas primeiras experiências de EaD pós internet, na qual a tecnologia era o foco central.

As políticas de formação continuada de professores tendem ao uso da educação a distância (EaD) incorporando as novas tecnologias, o que resulta no uso intensivo do computador e da internet. Esta nova forma de $\mathrm{EaD}$ tem provocado um significativo debate público sobre seu uso, resultando em injustificadas críticas extremamente desfavoráveis à EaD. (Vieira, 2011, p. 6).

A estratégia de "tentativa e erro" com a introdução das TICs na educação reforçaram críticas e preconceito. Levy (1993) relata o caso do insucesso da introdução dos computadores nas escolas francesas, nos anos 80, como um caso típico da falta de planejamento e da pedagogia citada por Castells.

Dois importantes desafios para a compreensão do uso da internet na sociedade em rede, segundo Castells, seriam: $a$ ideia da liberdade - as redes propiciam comunicação livre e global, mas a infraestrutura tem dono, normalmente os donos do capital; a exclusão das redes ser delas excluído, é ser marginalizado. "Os mecanismos de proteção social em que a paz social, a parceria de trabalho e segurança pessoal se fundavam precisam ser definidos no novo contexto socioeconômico" (Castells, 2003, p. 227)

Além das questões de inclusão/exclusão tecnológica que, em nossa visão, tem sido bem discutidas até os dias atuais, a educação apoiada pelas tecnologias da informação e comunicação, sobretudo a EaD, apresentariam outros desafios no início desse século.

A globalização é, de certa forma, o ápice do processo de internacionalização do mundo capitalista. "No fim do século XX e graças aos avanços da ciência, produziu-se um sistema de técnicas presidido pelas técnicas da informação, que passaram a exercer um papel de elo entre as demais, unindo-as e assegurando ao novo sistema técnico uma presença planetária" (SANTOS, 2000, p. 12). Nesse sentido, as tecnologias aliadas aos organismos internacionais promovem um mercado global que resulta numa forma ainda mais perversa de globalização.

Assim, Harvey (2008) corrobora Santos (2000), Bauman (1990), Levy (1993), dentre outros, que apontam a velocidade com que as mudanças têm ocorrido neste mundo globalizado sob a hegemonia do capital.

O mais interessante na atual situação é a maneira como o capitalismo está se tornando cada vez mais organizado através da dispersão, da mobilidade geográfica e das respostas flexíveis nos mercados de trabalho, nos processos de trabalho e nos mercados de consumo, tudo isso acompanhado por pesadas doses de inovação tecnológica, de produto e 
institucional.[...]

O acesso à informação, bem como o seu controle, aliados a uma forte capacidade de análise instantânea de dados, tornaram-se essenciais à coordenação centralizada de interesses corporativos descentralizados. (Harvey, 2008, p. 150 151).

Nesse sentido, as tecnologias da informação que atendem, num primeiro momento aos desígnios do capital é, por conseguinte, apropriada pela educação como "fórmula salvadora" na visão de alguns autores, tornando-se o cerne do processo pedagógico nas primeiras iniciativas de EaD pós-internet.

Os países desenvolvidos perversamente incluem saberes e tecnologias que instalam "no pensamento tecnológico do país subdesenvolvido os conceitos modeladores da alienação, da qual depois somente com extrema dificuldade e à custa de dolorosas lutas se libertará" (Vieira Pinto, 2005, p. 276).

É preciso, portanto, uma revolução na educação, pois a própria luta de classe é combatida pela doutrina neoliberal, dificultando cada vez mais que se enxergue o espírito desumano por traz de suas premissas, caracterizadas pelo cunho excludente do capitalismo, mantenedor dos status quo das desigualdades em que poucos têm muito e muitos vivem na miséria. Sendo assim, a mudança só será possível se pensarmos em uma educação emancipadora com políticas públicas e práticas mais includentes.

A sociedade do conhecimento, ao mesmo tempo em que encerra a promessa de emancipação, porta também a ameaça do surgimento de formas mais profundas de dominação, pois pode acarretar o mundo da vigilância constante e da reificação completa do humano, agora convertido em capital, quando a heterorregulação do mercado impõe-lhe a obrigação do aprender ao longo de toda a vida ou da danação eterna da não empregabilidade no mercado flexível. (Barros, 2014 p. 206).

As mudanças no mundo do trabalho promovidas, sobretudo, a partir do processo de acumulação flexível do capital, caracterizadas pelo abandono da rigidez e adoção da flexibilidade passam a exigir um novo profissional, dotado de flexibilidade e capacidade para aprender continuamente (Harvey, 2008).

a tecnologia que surge em determinado contexto e é posteriormente apropriada, se torna, num segundo momento, resultado da intervenção do homem em função do contexto social e temporal em que vive. Logo, ao mesmo tempo em que a tecnologia transforma a sociedade, é por esta transformada, resultado dos diversos usos e aplicações que recebe. (Santos Neto \& Mill, 2018, p. 124).

Dessa forma, a educação enquanto tecnologia molda e é moldada pela sociedade e a educação a distância, portanto, seria a ferramenta adequada para promover a formação continuada dos profissionais baseada nos preceitos neoliberais atendendo a alguns desses princípios básicos e essenciais ao Estado Neoliberal - a formação contínua ao longo da vida, em atendimento às exigências de organismos internacionais e a formação em serviço, dispensando a contratação de novos profissionais (, 2007).

A relação que se estabelece entre políticas e concepções de formação docente, o quanto é (ou pode) ser moldada e reconfigurada pelos interesses da política educacional na perspectiva de padronização, neste caso, especialmente pelo trabalho dos profissionais da educação como bolsistas, ratificando uma prática de raízes neoliberais e que, infelizmente, faz parte do atual modelo de educação superior a distância fomentado pela Universidade Aberta do Brasil. (2015, p. 216).

Reforçamos aqui a preocupação sugerida por Santos (2000) e Castells (1999) sobre o uso despótico da internet. "As políticas públicas educacionais devem incorporar a necessidade social de discussão sobre o modo como tais recursos tecnológicos ressignificam as características das teorias e práticas pedagógicas e dos processos de construção das identidades 
dos agentes educacionais" (, 2015, p. 218).

Corroborando Berbat (2015), Cavalcanti (2016) aponta que as bases que sustentaram a expansão da EaD no país foram o advento das tecnologias da informação e comunicação e da sociedade da informação, como partes das políticas nacionais apoiadas nas orientações dos organismos internacionais do final do século XX e início do século XXI.

As influências dos organismos internacionais, principalmente do BM, nas políticas públicas de formação do professor no Brasil, se manifestam nas políticas curriculares, na formação inicial e continuada dos professores, na reformulação dos textos e documentos legais e na avaliação dos índices observados para medir a eficiência e eficácia do sistema educacional brasileiro. (Otte, 2016, p. 181).

Tal influência, já apontada por outros autores, demonstram os desafios para se praticar uma EaD de forma democrática e emancipadora.

A formação do professor é contínua. Começa no curso de graduação e permeia toda a sua vida profissional, seja em cursos de pós-graduação, seja em cursos de curta duração, seja em seminários, seja em eventos, seja em reuniões pedagógicas, ou em momentos de avaliação da sua prática de ensino, seja ainda nas reflexões que ele próprio faz sobre sua prática. Os meios tecnológicos facilitam hoje a oferta e o desenvolvimento desses cursos. (Otte, 2016, p. 181).

Assim como pregam os organismos internacionais apoiados na agenda neoliberal e na acumulação flexível, a formação é por toda a vida e a EaD é o meio eficaz para melhor formar os profissionais na sociedade do conhecimento. Ela vai ganhando espaço ao longo dos anos e se consolidando como lócus prioritário para os programas de formação inicial de professores, representado, no caso da esfera pública, pela Universidade Aberta do Brasil. O modelo de estruturação da UAB é bastante questionado, uma vez que por um lado gozava de benefícios do governo central como no caso da inexigibilidade de processo avaliativo para credenciamento para oferta de cursos $\mathrm{EaD}$ e por outro, era apoiada num sistema de financiamento instável que se comprometeria no futuro. O Quadro 2 a seguir mostra a evolução de credenciamento para IES públicas entre 206 e 2017.

Quadro 2 - Evolução de credenciamentos para IES públicas de 2006 a 2017*.

\begin{tabular}{|c|c|c|}
\hline Ano & Portaria/Decreto & Descrição \\
\hline 2006 & Portaria $\mathrm{n}^{\circ} 873$, de 07 de abril & $\begin{array}{l}\text { Credencia todas as instituições federais de ensino superior para oferta de } \\
\text { cursos superiores a distância no âmbito da UAB. }\end{array}$ \\
\hline 2008 & Portaria $\mathrm{n}^{\circ} 1.050$, de 22 de agosto & $\begin{array}{l}\text { Revoga a Portaria } n^{\circ} 873 / 2006 \text { e credencia } 33 \text { IES públicas para oferta de } \\
\text { cursos superiores a distância no âmbito da UAB. }\end{array}$ \\
\hline 2009 & Portaria $\mathrm{n}^{\circ} 858$, de 04 de setembro & $\begin{array}{l}\text { Revoga a Portaria } n^{\circ} 1.050 / 2008 \text { e credencia } 49 \text { instituições públicas para } \\
\text { ensino superior a distância no âmbito da UAB. }\end{array}$ \\
\hline 2010 & & 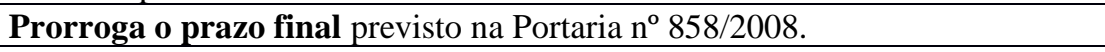 \\
\hline 2010 & $\begin{array}{l}\text { Portaria } \mathrm{n}^{\circ} 1.369 \text {, de } 17 \text { de } \\
\text { dezembro }\end{array}$ & $\begin{array}{l}\text { Revoga a Portaria } \mathrm{n}^{\circ} 858 / 2008 \text { e credencia } \mathbf{5 1} \text { instituições públicas para o } \\
\text { ensino superior a distância no âmbito da UAB e } 768 \text { polos de apoio } \\
\text { presencial. }\end{array}$ \\
\hline 2017 & $\begin{array}{l}\text { Decreto } n^{\circ} 9.057 \text {, de } 25 \text { de maio de } \\
2017\end{array}$ & $\begin{array}{l}\text { Credencia todas as IES federais que ainda não possuíam credenciamento } \\
\text { para oferta de cursos superiores e lato sensu a distância. }\end{array}$ \\
\hline
\end{tabular}

* Em 2017 foi o último credenciamento automático de IES federais para oferta de cursos a distância.

Fonte: Brasil (2006; 2008; 2009; 2010); Brasil (2017) - grifos nossos.

O Quadro 2 mostra que no curto período de implementação da UAB (2006 a 2010) foram emitidas cinco portarias de credenciamento para instituições públicas ofertarem educação superior a distância. Isso mostra, por um lado, a implantação de uma política de formação de professores pautada no aligeiramento das ações, e por outro, entendemos como um engodo do governo para com as instituições públicas, uma vez que se dava o credenciamento, mas não oferecia condições para que as IES 
realizassem cursos de qualidade.

É inegável que a política macro influencia demasiadamente as universidades federais (Amaral, 2008; Oliveira, 2000; Sguissardi, 2009), principalmente os delineamentos do Sistema UAB, que impactam nas instituições de ensino superior e nos polos que compõem esse sistema, na condução da EaD. As 56 vagas autorizadas, para contratação de professores e de funcionários técnico-administrativos não são suficientes para alavancar a EaD na Universidade, da mesma forma que o financiamento para projetos específicos, de forma descentralizada, não entrando como orçamento anual das instituições, é um ponto de estrangulamento e algo a ser questionado. (Faria, 2011, p. 222).

Nesse cenário é que se desenvolvem as primeiras experiências de formação de professores a distância no âmbito da UAB. Assim, as instituições começaram a estruturar seus órgãos internos que atuam com $\mathrm{EaD}$, sob diversas formas: secretarias, departamentos, coordenações, dentre outras possibilidades dentro da estrutura de instituições públicas.

Faria (2011) descreveu a estrutura organizacional da EaD na Universidade Federal de Goiás - UFG, e apontou os principais desafios nessa estruturação. A expansão da $\mathrm{EaD}$ na rede privada, bem como o crescimento da UAB tem trazido muitas discussões.

Essa realidade tem sido questionada, inclusive durante a Conferência Nacional de Educação em 2010 (Zuin, 2010), pelo frisson da EaD, com altos índices de concentração de matrícula nas instituições privadas, sobretudo, em cursos de formação de professores. O movimento de expansão e de frisson, portanto, tem contribuído para a construção de narrativas simbólicas, que revelam, ora preconceitos, ora deslumbramentos com a EaD. Isso se deve, principalmente, à predominância do modelo de EaD baseado na perspectiva fordista (Belloni, 1999; Toschi, 2005), com produção em massa, produtos e processos estandardizados e pacotes educacionais. É preciso, porém, desencadear processos mais interativos e de valorização de trocas e de encontros dialógicos a partir das práticas da EaD (Toschi, 2005; Feenberg, 2001; Alonso, 2009). (Faria, 2011, p. 211-218).

Para a autora, embora a EaD esteja ancorada em preceitos neoliberais, existe e é necessária repensá-la, incluindo opções para que possa promover a democratização e emancipação social, visto que a $\mathrm{EaD}$ bem estruturada e oferecendo ensino de qualidade pode estar mais voltada ao acesso - ingresso, permanência e alcance do conhecimento -possibilitando maior inclusão educacional.

Por sua vez, Costa (2012) apontou que a inclusão da EaD na legislação brasileira, sobretudo na Lei $n^{\circ}$ 9.394/96, ocorreu influenciada em um conjunto de forças para que sua prática fosse em favor da governamentabilidade da população.

Com o emprego da EaD não é mais preciso das estruturas, o confinamento, há um deslocamento dos mecanismos de poder, que deixa de ser realizado somente através do espaço fechado, para ser alcançado através de meios como a $\mathrm{EaD}$, em suas associações com as TIC. [...] o objetivo dessa prática no cenário brasileiro tem sido o de oferecer à população, condições de se adaptar para as diferentes tarefas e de buscar, por si mesmos, um aperfeiçoamento 'ininterrupto', de modo a alcançar determinadas capacidades para viverem num mundo em rápida transformação. (Costa, 2012, p. 154 - grifo da autora).

Nesse sentido, a busca pela aprendizagem ininterrupta, e de forma autônoma, vai ao encontro da proposta neoliberal de UNESCO (1997): “aprender a aprender, para beneficiar-se das oportunidades oferecidas pela educação ao longo de toda a vida" (UNESCO, 1997, p. 101). Esse fato ressoa mais como um engodo que leva o indivíduo a buscar busca sempre maior qualificação para atender exclusivamente às exigências do mercado o que nem sempre se resulta em melhoria de qualidade de vida.

Assim, a sociedade capitalista resguarda com vigor não apenas seu sistema de educação contínua, mas simultaneamente também a doutrinação permanente, mesmo quando a doutrinação que impregna tudo não parece ser o que é, por ser tratada pela ideologia vigente "consensualmente internalizada" como o sistema de crença positivo compartilhado de maneira legítima pela "sociedade livre" estabelecida e totalmente não objetável. (Mészáros, 2008, p. 
82 - grifos do autor).

Aprender a aprender, aprender eternamente, coloca-se sob a forma de algo inevitável e paradoxal: se por um lado o discurso da empregabilidade propõe ao cidadão a liberdade e emancipação, por outro lhe impõe as premissas de doutrinação capitalista e o torna refém desse aprendizado contínuo.

É este continuum educativo, coextensivo à vida e ampliado às dimensões da sociedade, que a Comissão entendeu designar, no presente relatório, pela expressão "educação ao longo de toda a vida". Em seu entender, é a chave que abre as portas do século XXI e, bem além de uma adaptação necessária às exigências do mundo do trabalho, é a condição para um domínio mais perfeito dos ritmos e dos tempos da pessoa humana. (UNESCO, 1997, p. 104 - grifos do autor).

Se por um lado essa chave se mostra libertadora, por outro, na verdade, se constitui na "chave da prisão", cujo intuito é nos tornar prisioneiros do consumo e mercadorias vendidas a um mercado de muitas oportunidades e poucas condições de igualdade, do qual a educação superior se tornou uma delas.

As políticas públicas nacionais vêm direcionando a educação superior a distância, especialmente para servir à formação inicial e continuada de professores, como forma de aumentar a quantidade de professores e a eficiência dessa formação. De fato, a EaD permite o atendimento de mais professores com melhor relação eficiência versus custos, utilizando as potencialidades da comunicação em massa e da reduzida demanda por estruturas como salas de aula. (Nass, 2012, p. 161).

Nesse sentido, o governo se apropria do discurso neoliberal e faz sua parte: institucionaliza-se um programa de expansão com baixo custo, apoiado em decretos, leis e normativas que favorecem o aligeiramento da formação e a expansão da oferta de EaD na formação de professores. Do outro lado, as universidades públicas e os institutos federais tentam, com os recursos limitados, implementar seus programas e cursos a distância num ambiente de incerteza.

Lima (2013, p. 231) assevera que na implementação de políticas públicas para $\mathrm{EaD}$ não observou as primeiras fases do ciclo da política pública (definição de problemas, construção da agenda e formulação). Parte do descompasso entre as políticas propostas pelo estado e a execução pelas universidades se apoia nesse fato.

Assim, as políticas são formuladas e posteriormente aplicadas. No caso da EaD no Brasil, a política contribui para uma regulamentação e estruturação a favor da educação privada. O descompasso entre interlocutores locais, internacionais e a efetiva política consolidada é vista em documentos e ações desenvolvidas no âmbito da EaD no país. A respeito disso, podemos citar a divergência presente no Decreto $n^{\circ} 9.057$ em relação às orientações do Conselho Nacional de Educação, propostas no Parecer CNE/CES n ${ }^{\circ}$ 564/2015 que dispõe sobre as diretrizes e normas nacionais para a oferta de programas e cursos de educação superior na modalidade a distância. O Quadro 3 a seguir aponta as principais divergências entre o Parecer CNE/CES n $564 / 2015$ e o Decreto n 9.057/2017. 
Quadro 3- Divergências entre o Decreto no 9.057/2017 e o Parecer CNE/CES nº 564/2015.

\begin{tabular}{|c|c|c|}
\hline Temas divergentes & Parecer CNE/CES 564/2015 & Decreto 9.057/2017 \\
\hline $\begin{array}{l}\text { Decreto } \mathrm{n}^{\circ} \\
5.622 / 2005\end{array}$ & Mantém o Decreto n ${ }^{\circ} 5.622 / 2005$. & Revoga o Decreto 5.622/2005. \\
\hline Pessoal da educação & $\begin{array}{l}\text { Caracteriza as funções de Docentes e Tutores de } \\
\text { EaD. }\end{array}$ & Não cita nada a respeito desses profissionais. \\
\hline Educação básica & Não trata a educação básica no parecer. & $\begin{array}{l}\text { Inclui prerrogativas para oferta de educação básica a } \\
\text { distância no seu artigo } 8^{\circ} \text {. Atribui competência aos } \\
\text { municípios para de autorizar cursos e funcionamento de } \\
\text { instituições a oferta de educação a distância no ensino } \\
\text { fundamental nos termos da Lei no } \mathrm{n}^{\circ} 9.394 / 96 \text {. }\end{array}$ \\
\hline $\begin{array}{l}\text { Material didático e } \\
\text { avaliação }\end{array}$ & $\begin{array}{l}\text { É dedicado um capítulo para tratar sobre essas } \\
\text { temáticas. }\end{array}$ & Não contempla material didático no seu texto. \\
\hline $\begin{array}{l}\text { Avaliação da } \\
\text { aprendizagem }\end{array}$ & $\begin{array}{l}\text { Mantém o prevalecimento das avaliações } \\
\text { presencial sobre aquelas feitas a distância. } \\
\text { Previstas no Decreto } n^{\circ} 5.622 / 2005 \text {. }\end{array}$ & $\begin{array}{l}\text { Não há obrigatoriedade de avaliações presenciais, apenas } \\
\text { se forem previstas nos projetos pedagógicos. }\end{array}$ \\
\hline $\begin{array}{l}\text { Polo de Apoio } \\
\text { presencial }\end{array}$ & $\begin{array}{l}\text { Polos próprios da instituição. } \\
\text { Credenciados juntamente com o ato de } \\
\text { credenciamento EaD ou em processo próprio. }\end{array}$ & $\begin{array}{l}\text { Permite a terceirização de polos de apoio presencial por } \\
\text { outras pessoas jurídicas. } \\
\text { Basta comunicar a abertura do polo. }\end{array}$ \\
\hline $\begin{array}{l}\text { Credenciamento } \\
\text { para oferta de curso } \\
\text { a distância }\end{array}$ & $\begin{array}{l}\text { Credenciamento individualizado para graduação e } \\
\text { pós-graduação, permitindo aditamento de uma } \\
\text { modalidade para outra. } \\
\text { Há a necessidade de curso presencial para solicitar } \\
\text { credenciamento para EaD. }\end{array}$ & $\begin{array}{l}\text { Basta um credenciamento (graduação ou pós-graduação } \\
\text { lato sensu) para ofertar ambas modalidades. } \\
\text { É permitido o credenciamento de instituição } \\
\text { exclusivamente para oferta de curso a distância. } \\
\text { Credencia todas as IES Federais para oferta de EaD durante } \\
05 \text { anos. }\end{array}$ \\
\hline
\end{tabular}

Fonte: Brasil (2017), CNE (2015b).

Nesse prisma, mesmo com a interlocução entre diversos atores na proposição de políticas públicas para a educação, o Estado brasileiro acaba por se apropriar de proposições de cunho neoliberal, atendendo as premissas das organizações internacionais e do mercado.

Ao mesmo tempo em que se nota uma certa estabilidade e adaptabilidade das políticas, verifica-se um ir e vir regulatório com a criação de mais políticas ao invés de fortalecer e institucionalizar as já existentes. Resumindo, a centralidade em programas é um limite para o desenvolvimento das suas políticas, com múltiplos interlocutores, sem uma base comum dessas políticas para a busca de uma diretriz comum. (Lima, 2013, p. 233).

O principal fator que contribui para isso é o fato de a EaD pública ser tratada como política de governo e não de Estado. Dessa forma, não há tempo hábil para que uma política se fortaleça, ficando a mesma à mercê do entra e sai de gestores, normalmente escolhidos não por competência técnica ou por carreira, mas por questões meramente políticas (Lima, 2013).

Assim, o fato de a institucionalização da EaD nas IES federais não acontecer na prática e uma regulação mais flexível acabam por contribuir para o processo de privatização da educação. Somamos a isso o fato de que o "Regime de Colaboração" entre União e entes federativos previstos no artigo $2^{\circ}$ do Decreto $n^{\circ} 5.800$ que cria a UAB, na prática também não se efetivou pelas mesmas questões postas anteriormente.

Sob o aspecto financeiro, a disponibilidade de recursos do Governo Federal faz com que haja uma relação de dependência dos demais entes criando subordinação de estados e municípios à União. Dessa forma, sob esse aspecto fica subsumida no conceito de colaboração uma relação de subordinação, na qual a alternativa de Estados e Municípios é acatar as propostas publicadas nos editais da CAPES em troca dos recursos do governo federal, parecendo assim, mais uma hierarquia que subordina à União os demais entes, do que uma colaboração efetiva. A atuação da União está mais próxima de uma coordenação federativa para que o Sistema UAB seja mantido do que 
uma colaboração entre os entes federados para que do conjunto dos esforços possa se consolidar uma política responsável, construída sob as bases democráticas entre entes federados autônomos para oferta de educação superior. (Santos, 2013, p. 140-141).

Um dos pontos nevrálgicos da UAB é o acervo bibliográfico dos cursos, que é exigido pela CAPES e de responsabilidade dos mantenedores de polos (estado ou município). Branco (2014) aponta que o acervo bibliográfico dos polos é fraco mediante a necessidade de formação superior de professores. Portanto, como a prioridade dos investimentos dos entes federados, conforme a constituição é para ensino fundamental (município) e médio (estados e distrito federal), o investimento em cursos superiores não é prioridade desses parceiros. O Decreto $n^{\circ}$ 9.235/2017 passou a permitir acervo digital para fins de avaliação e reconhecimento de curso, contudo, a maioria dos polos não possuem acesso a tal acervo, quando muito a sites de bibliotecas e repositórios (Santos NETO, 2019).

Reforça-se, assim, o processo de desresponsabilização da União em relação a esse aspecto.

Também os coordenadores da UAB, responsáveis pela gestão no interior das universidades, são afetados pelas vontades políticas nos momentos de trocas de reitores, de forma que mesmo podendo ser entendido como uma política de Estado, o regime de colaboração do Sistema UAB, complexo pela sua natureza, demonstra vulnerabilidade e necessidade de aperfeiçoamento nesses aspectos. (Santos, 2013, p. 141).

O programa UAB está sujeito, portanto, a uma descontinuidade nos diversos níveis federativos, tanto sob aspectos políticos, como de gestão e financeiros. Na esfera federal destacam-se a falta e a descontinuidade de financiamento e na esfera municipal e estadual as questões são mais voltadas à manutenção dos polos de apoio presencial.

Assim, uma dúvida paira sobre a continuidade do programa UAB apoiada na ideia de descontinuidade orçamentária, da massificação promovida pela falta de recursos e do processo de desresponsabilização.

\section{Considerações Finais}

Como desencadeador inicial do processo de expansão da EaD destacou-se o advento das TDIC, sobretudo a internet, que promoveu maior flexibilidade no processo de comunicação, novas possibilidades para a EaD, sobretudo no tangente à comunicação síncrona, permitindo que o processo ocorra ao mesmo tempo em espaços diferentes.

Não menos importante, as orientações de organismos internacionais, sobretudo o Banco Mundial, FMI e UNESCO, segundo os autores, foram os principais influenciadores das políticas públicas de formação de professores no país.

Outro fator fundante foi a transição do regime de acumulação "rígida" do capital no modelo fordista para o modelo de acumulação flexível, que passa a exigir segundo Harvey (2008), Antunes (2002), Montaño e Duriguetto (2011) um novo perfil de trabalhador, mais flexível, com capacidade de autoaprendizagem, que aprenda continuamente e de preferência em serviço.

No tocante ao acesso e democratização, ofertar pela UAB preferencialmente cursos de formação de professores não significa garanti-los, uma vez que os estudantes não terão disponível um rol de cursos em que possam escolher de acordo com seu interesse e vocação, bem como a massificação e o aligeiramento proporcionado pelo parco financiamento se distanciam da oferta de educação emancipatória.

Outro aspecto que destacamos é em relação à legalização como falácia de uma educação de qualidade. O período entre 2005 a 2010 foi caracterizado pela legalização da EaD no Brasil: nesse período houve um grande empenho por parte do Ministério da Educação em se promover a EaD no país. Foram publicadas cinco portarias de credenciamento automático para instituições públicas de ensino superior, regulamentado o artigo 80 da LDB e criado o Programa UAB, demonstrando o interesse do governo central pela migração formação de professores para a modalidade a distância, percebidos por meio do grande volume de decretos, portarias, dentre outros, tais como: o Decreto $\mathrm{N}^{\mathrm{o}} 5.622 / 2005$, o Decreto $\mathrm{n}^{\mathrm{o}} 5.800 / 2006$, as portarias 
MEC de credenciamento das IES públicas (873/2006, 1.050/2008, 858/2009, 1.043/2010 e 1.369/2010) de forma unilateral sem verificação das condições estruturais das IPES para oferta de EaD. Se por um lado houve um empenho na regulamentação como formalização do interesse do poder executivo na $\mathrm{EaD}$, por outro as ações propriamente ditas de apoio ao programa $\mathrm{UAB}$ não ocorreram.

Outros embasamentos legais foram a Lei 11.273, de 06 de fevereiro de 2006 que prevê a concessão de bolsas de estudo e pesquisa para participantes de programas de formação inicial e continuada de professores para a educação básica; da Resolução CD/FNDE $n^{\circ}$ 26, de 05 de junho de 2009, que estabelece orientações para o pagamento de bolsas no âmbito da UAB, bem como da Portaria MEC n 318, de 02 de abril de 2009, que transfere para a CAPES a operacionalização do Sistema Universidade Aberta do Brasil (UAB).

No tocante ao regime de colaboração proposto por meio do Decreto ${ }^{\circ} 5.800$ que cria a UAB, no qual os entes federativos participam com a manutenção da estrutura de polos de apoio presencial, observamos que não houve a efetiva implementação do regime de colaboração, uma vez que, pelo fato de a UAB ser programa de governo, tanto em nível federal como no nível dos entes federativos, está sujeita a descontinuidades, promovidas pelo não cumprimento de uma das partes colaboradoras.

Assim, como visto, por parte da União a falta de repasses financeiros, a escassez de recursos, ou a falta de efetiva política de Estado para a UAB implicou descontinuidades nas ofertas dos cursos UAB. Por outro lado, em relação aos polos de apoio presenciais, observou-se que a cada gestão municipal ou estadual, pode-se dispensar maior ou menor investimento nos polos de apoio. Outro ponto importante é que pelo fato de a legislação delegar ao município e estados o atendimento prioritário à educação básica, há menor interesse ou maior dificuldade para se investir em polos para o ensino superior. Esse investimento, no entanto, independe do tamanho do município e de seu PIB. Em estudo preliminar por nós elaborado notamos que municípios de menor PIB, com menor oportunidade de acesso ao ensino superior, valorizam mais o polo presencial que municípios maiores.

A expansão da educação a distância no Brasil se inicia após a promulgação da LDB 9.394/1996, incentivada pelas prerrogativas legais ali postas. O período entre a LDB e o início desse século foi marcado pelo crescimento do uso da internet no país que traria condição para que a Educação a Distância se firmasse enquanto modalidade de ensino. Sob um ar de desconfiança e preconceito, sua prática vai aos poucos sendo implantada nas universidades públicas e privadas, sendo que, nas segundas encontrou ambiente demasiadamente propício para seu enraizamento e consolidação.

Assim, concluímos que o Programa UAB se encontra em um processo de fenecimento no qual dois fatores são preponderantes: o parco e descontinuo financiamento e o distanciamento de uma educação emancipatória com um sistema precarizado de pessoal e cada vez mais as IES obrigadas a reduzirem seus custos a aproximarem-se da educação mercadoria.

\section{Referências}

Antunes, R. (2002). Os sentidos do trabalho: ensaio sobre a afirmação e a negação do trabalho. (6a ed). Boitempo.

Barros, J. N. S. (2014). Democracia e utopia na sociedade do conhecimento: reflexões sobre a educação a distância. (Tese de Doutorado) - Faculdade de Educação, Universidade de São Paulo.

Barroso, J. (2005). O estado, a educação e a regulação das políticas públicas. Revista Educação e Sociedade, Campinas, 26 (92)725-751, http://www.cedes.unicamp.br. https://doi.org/10.1590/S0101-73302005000300002.

Bauman, Z. (1990). Globalização: as consequências humanas. Jorge Zahar.

Berbat, M. C. (2015). Pró-licenciatura e a experiência de formação de professores para a educação básica. (Tese de Doutorado) -Universidade Estadual de Campinas, Faculdade de Educação.

Bogdan, R. C. \& Biklen, S. K. (1994). Investigação qualitativa em educação: uma introdução à teoria e aos métodos. Porto Editora.

Branco, Juliana Cordeiro Soares. (2014). A formação de professores a distância no Sistema UAB: análise de duas experiências em Minas Gerais. 2014. (Tese 
de Doutorado). Universidade Federal de Minas Gerais, Faculdade de Educação, Belo Horizonte.

Brasil. Coordenação de Aperfeiçoamento de Pessoal de Nível Superior. (2018) Ofício $n^{o}$ 245/2018-GAB/PR/CAPES. Nota do Conselho Superior da Capes ao Ministro da Educação. Brasília: Coordenação de Aperfeiçoamento de Pessoal de Nível Superior https://sei.capes.gov.br/sei/controlador_externo.php?acao=documento_conferir\&codigo_verificador=0746852\&codigo_crc=6755A444\&hash_download=ef5e 65b749e9b6a0c124c56e438345f0dbb86d4b097fccd29f4b4221365642ee971b5a5e507aea925d83d67d1d4d79f08696fa5be30b507aa19122ff68c396a9\& visualiz acao=1\&id_orgao_acesso_externo=0.

Brasil. Decreto $n^{\circ}$ 9.057, de 25 de maio de 2017. (2017). Regulamenta o art. 80 da Lei $n^{\circ} 9.394$, de 20 de dezembro de 1996, que estabelece as diretrizes e bases da educação nacional. Brasília, DF: Câmara dos Deputados, 2017. http://www2.camara.leg.br/legin/fed/decret/2017/decreto-9057-25-maio-2017784941-publicacaooriginal-152832-pe.html.

Brasil. Ministério da Educação. (2008). Portaria $n^{\circ} 1.050$, de 22 de agosto de 2008. Credencia em caráter experimental, exclusivamente para a oferta de cursos superiores na modalidade a distância aprovados no âmbito da UAB IES públicas. Brasília, DF: Ministério da Educação. http://www.abed.org.br/site/pt/midiateca/noticias_ead/365/2008/09/portaria_n_1.050,_de_22_de_agosto_de_2008.

Brasil. Ministério da Educação. (2010). Portaria $n^{o}$ 1.369, de 17 de dezembro de 2010. Credencia Instituições Públicas de Educação Superior, vinculadas ao Sistema Universidade Aberta do Brasil. MEC. https://edutec.unesp.br/images/stories/portarias/portaria\%20normativa\%201369\%20dia\%2007-12-2010.pdf.

Brasil. Ministério da Educação. (2009). Portaria n ${ }^{o}$ 318, de 02 de abril de 2009. Transfere à Capes a operacionalização da UAB. DF: Ministério da Educação. http://www.capes.gov.br/images/stories/download/legislacao/Portaria318_de020409_UABparaCapes.pdf.

Brasil. Ministério da Educação. (2006). Portaria $n^{\circ}$ 873, de 07 de abril de 2006. Autoriza, em caráter experimental a oferta de cursos superiores a distância nas Instituições Federais de Ensino Superior. Ministério da Educação. http://portal.mec.gov.br/sesu/arquivos/pdf/portarias/portaria873.pdf.

Brasil. Ministério da Educação. (2003). Referenciais de Qualidade para educação a distância. Ministério da educação. http://portal.mec.gov.br/seed/arquivos/pdf/referenciaisead.pdf.

Castells, M. (2003). A galáxia da internet: reflexões sobre a internet, os negócios e a sociedade. Jorge Zahar Editor.

Conselho Nacional de Educação (Brasil). (20015). Parecer CNS/CES n ${ }^{\circ}$ 564, de 10 de dezembro de 2015. Diretrizes e Normas Nacionais para a oferta de Programas e Cursos de Educação Superior na Modalidade a Distância. Brasília: Conselho Nacional de Educação. http://portal.mec.gov.br/index.php?option=com_docman\&view=download\&alias=31361-parecer-cne-ces-564-15-pdf\&category_slug=dezembro-2015-

pdf\&Itemid=30192

Costa, J. R. M. (2015). O processo de institucionalização da educação a distância no Brasil. (Tese de Doutorado). Universidade Federal do Rio Grande do Sul, Faculdade de Educação;

Costa, M. L. F. (2010). Políticas públicas para o ensino superior a distância e a implementação do sistema Universidade Aberta do Brasil no Estado do Paraná. (Tese de Doutorado). Universidade Estadual Paulista, Faculdade de Educação, Araraquara.

Faria, J. G. (2011). Gestão e organização da educação a distância em universidade pública: um estudo sobre a Universidade Federal de Goiás. (Tese de Doutorado). Universidade Federal de Goiás, Faculdade de Educação, Goiânia.

Freitas, H. C. L. (2007). A (nova) política de formação de professores: a prioridade postergada. Educação e Sociedade, Campinas, 28 (100, Especial) 12031230. http://www.scielo.br/pdf/es/v28n100/a2628100. https://doi.org/10.1590/S0101-73302007000300026.

Fundo Nacional de Desenvolvimento da Educação (Brasil). (2006). Resolução FNDE/CD $n^{\circ} 44$, de 29 de dezembro de 2006. Estabelece orientações e diretrizes para a concessão de bolsas de estudo e de pesquisa a participantes dos cursos e programas de formação superior, no âmbito do Sistema Universidade Aberta do Brasil. Brasília: Fundo Nacional de Desenvolvimento da Educação. https://www.fnde.gov.br/acesso-ainformacao/institucional/legislacao/item/3119-resolu\%C3\%A7\%C3\%A3o-cd-fnde-n\%C2\%BA-44-de-29-de-dezembro-de-2006.

Gomes, F. G. (2006). Conflito social e welfare state: estado e desenvolvimento social no Brasil. Revista de administração pública, Rio de Janeiro, 40 (2) 201234. https://www.researchgate.net/publication/237745623_Conflito_social_e_welfare_state_Estado_e_desenvolvimento_social_no_Brasil. https://doi.org/10.1590/S0034-76122006000200003

Gomes, I. C. R. (2007). Formação de professores de $1^{a}$ a $4^{a}$ séries do Ensino Fundamental nas modalidades a distância e presencial: um estudo na Universidade Federal do Espírito Santo. (Tese de Doutorado). Universidade Federal de Minas Gerais, Faculdade de Educação, Belo Horizonte.

Guiotti, E. A. (2007). Educação a Distância: tendências predominantes na sua expansão, Brasil e Espanha. (Tese de Doutorado). Pontifícia Universidade Católica de São Paulo, Faculdade de Educação.

Harvey, D. (2008). Condição pós-moderna: uma pesquisa sobre as origens da mudança cultural. (17a ed.), Edições Loyola.

Instituto Nacional de Estudos e Pesquisas Educacionais (Brasil). (2016). Censo da educação superior: principais resultados. Brasília, DF: Instituto Nacional de Estudos e Pesquisas Educacionais. https://abmes.org.br/arquivos/documentos/censo_superior_tabelas.pdf.

Instituto Nacional de Estudos e Pesquisas Educacionais (Brasil). (2020). Censo da educação superior 2019: notas estatísticas. Brasília, DF: Instituto Nacional de Estudos e Pesquisas Educacionais. https://download.inep.gov.br/educacao_superior/censo_superior/documentos/2020/Notas_ Estatisticas_Censo_da_Educacao_Superior_2019.pdf.

Levy, P. (1999). Cibercultura. Editora 34.

Levy, P.(1993). Tecnologias da inteligência: o futuro do pensamento na era da informática. Editora 34.

Lima, D. C. B. P. (2013). Políticas públicas de EaD no ensino superior: uma análise a partir das capacidades do estado. (Tese de Doutorado). Universidade Federal do Rio de Janeiro, Instituto de Economia. 
Martelli, I. (2003). EAD: uma alternativa de políticas educacionais para a formação de professores. (Tese de Doutorado). Universidade Estadual Paulista, Faculdade de Educação, Marília.

Medeiros, S. (2012). Políticas de Educação a Distância na formação de professores da educação básica no Governo Lula da Silva (2003-2010): embates teóricos e políticos de um campo em disputa. (Tese de Doutorado). Universidade Federal de Goiás, Faculdade de Educação, Goiânia.

MÉSZÁRROS, István. (2008). A educação para além do capital. (2a ed.), Boitempo.

Mill, D. R. S. (2016). Educação a Distância: cenários, dilemas e perspectivas. Revista Educação Pública, Cuiabá. 25 ( 59, 2) 432-454.

Montaño, C. \& Duriguetto, M. L. (2011). Estado, Classe e movimento social. Editora Cortez.

Nascimento, A. S. R. (2012). As tecnologias digitais como dispositivo de poder: da Universidade Aberta no Brasil ao Sistema Virtual de aprendizagem do Brasil-MOODLE. (Tese de Doutorado). Universidade Federal da Paraíba, Faculdade de Educação, João Pessoa.

Nass, D. P. (2012). Licenciaturas a distância em Física e Química no Tocantins: trajetórias, possibilidades e limites. (Tese de Doutorado). Universidade de São Paulo, Instituto de Bioquímica, Física e Ciências, São Paulo.

Osório, M. R. V. (2010). Formação de professores na Universidade Aberta do Brasil (UAB): discursos que governam. (Tese de Doutorado). Universidade Federal de Pelotas, Faculdade de Educação, Pelotas.

Otte, J. (2016). Políticas Públicas de Formação Continuada de Professores para atuar na Educação a Distância/UAB: desafios e realidades no IFSul. (Tese de Doutorado). Universidade Federal de Pelotas, Faculdade de Educação, Pelotas.

Pessôa, M. P. (2006). A gestão dos projetos públicos de educação à distância no Paraná (1995-2005): contradições e perspectivas. (Tese de Doutorado). Universidade Estadual de Campinas, Faculdade de Educação, Campinas.

Ramos, I. J. (2013). Panorama das Licenciaturas de Ciência e Matemática no Brasil: Fragilidades, Ofertas e Tecnologias. (Tese de Doutorado). Universidade Cruzeiro do Sul, Faculdade de Educação, São Paulo.

Reis, A. S. (2002) Educação à Distância no Brasil: uma leitura sob a ótica da razão jurídica. (Tese de Doutorado). Universidade Federal de Minas Gerais, Faculdade de Educação, Belo Horizonte.

Sader, E. (2008). Prefácio. In: MÉSZÁRROS, István. A educação para além do capital. (2a ed.), Boitempo.

Santos Neto, V. B. (2019). A formação inicial de professores a distância no Brasil: os contornos e trajetórias do Sistema Universidade Aberta do Brasil na região do Triângulo Mineiro e Alto Paranaíba no período de 2013 a 2018. (Tese de Doutorado). Universidade Federal de Uberlândia, Faculdade de Educação, Uberlândia.

Santos Neto, V. B. \& Mill, D. R. S. (2018). Intensificação do trabalho docente e tecnologias digitais em pesquisas sobre educação no Brasil. Revista Emrede. Rio Grande, 5 (1) 123 - 136. https://www.aunirede.org.br/revista/index.php/emrede/article/view/289.

Santos, M. D. M. (2013). Avaliação do regime de colaboração do sistema Universidade Aberta do Brasil - UAB. (Tese de Doutorado). Pontifícia Universidade Católica do Paraná, Faculdade de Educação, Curitiba.

Santos, M. (2000). Por uma outra globalização: do pensamento único à consciência universal. Editora Record.

UNESCO. (1997) Educação um tesouro a descobrir: relatório para a UNESCO da Comissão Internacional sobre Educação para o século XXI. Brasília, DF: UNESCO.

Veltroni, A. L. (2005). Educação a distância no Brasil: instrumento de concretização do direito fundamental à educação. (Tese de Doutorado). Pontifícia Universidade Católica de São Paulo, Faculdade de Direito, São Paulo.

Vieira Pinto, Á. (2005). O conceito de tecnologia. Contraponto.

Vieira, M. P. A. (2011). A EAD nas políticas de formação continuada de professores. (Tese de Doutorado). Universidade Estadual de Campinas, Faculdade de Educação.

Wellen, H. A. R. (2011). Neoliberalismo, reforma do estado e o público-não-estatal: novos contornos entre o público e o privado. Revista Século XXI, 1 (2) 95 114.

Zeichner, K. M. (2013) Políticas de formação de professores nos Estados Unidos: como e por que elas afetam vários países no mundo. Autêntica editora. 